\title{
EAl Endorsed Transactions

\section{Evaluation method for network multimedia teaching quality of English based on information entropy}

\author{
Zhi-yu Zhou ${ }^{1}$, Mengye $\mathrm{Lu}^{2}{ }^{2 *}$ \\ ${ }^{1}$ Experimental and Training Centre, Shandong Management University, Jinan 250357, China \\ ${ }^{2}$ Institute of Economics and Management, Shandong Huayu Unversity of Technology, Dezhou 253000, China
}

\section{Abstract}

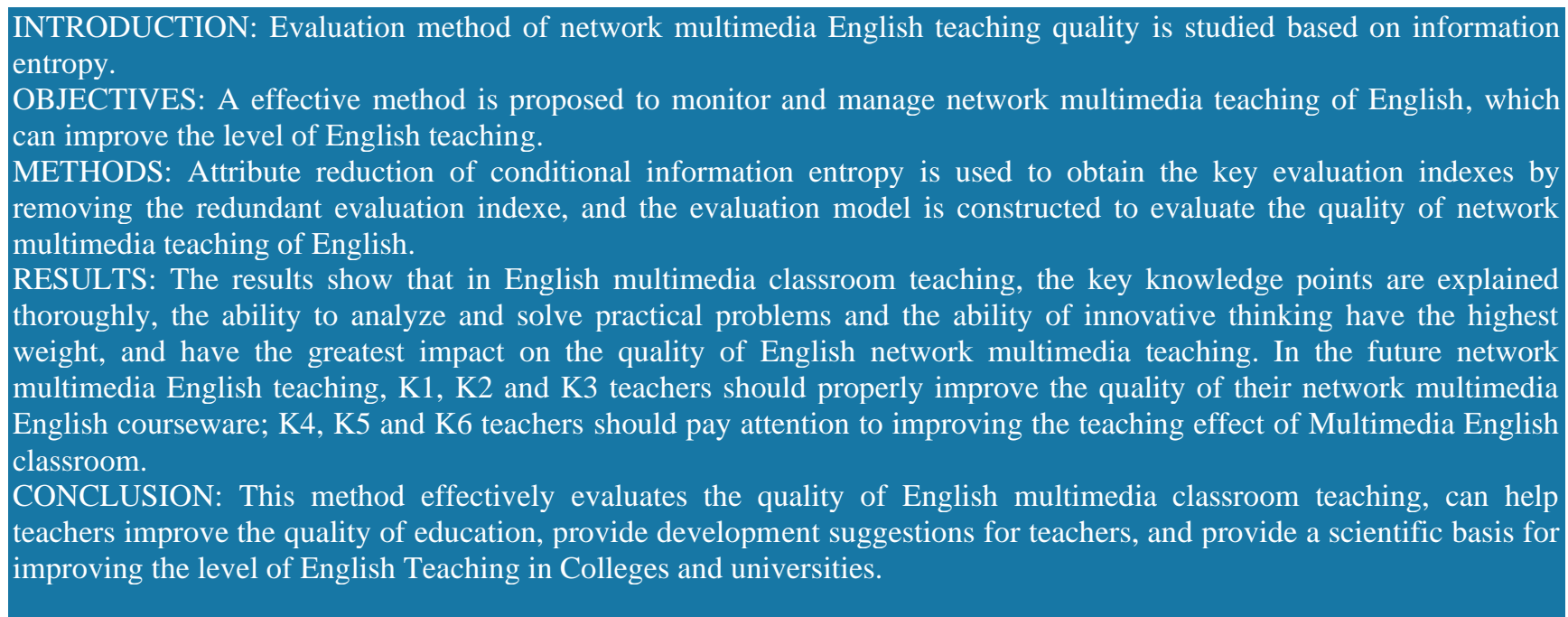

Keywords: Information entropy; Network multimedia; English teaching; Quality assessment; Attribute reduction; Evaluation model

Received on 11 December 2021, accepted on 17 January 2022, published on 26 January 2022

Copyright (C) 2022 Zhi-yu Zhou et al., licensed to EAI. This is an open access article distributed under the terms of the Creative Commons Attribution license, which permits unlimited use, distribution and reproduction in any medium so long as the original work is properly cited.

doi: 10.4108/eai.26-1-2022.173159

"Corresponding author. Email: 1my@mail.imu.edu.cn

\section{Introduction}

With the rapid development of information technology and the continuous expansion of its application field, information technology has entered the field of higher education. The application and popularization of network multimedia teaching, one of the manifestations of educational informatization, has been continuously improved in teaching links [1]. According to the requirements of relevant documents of the Ministry of Education, the proportion of required courses taught by network multimedia in colleges and universities under national key construction (ie. the "211 Project") shall not be less than $30 \%$, and that in general colleges and universities shall be $15 \%$. In response to this situation, colleges and universities across the country regard network multimedia teaching as an important aspect of teaching reform. The use of network multimedia teaching has become an important means of teaching in colleges and universities, especially the use of network multimedia in English teaching [2]. With the continuous popularization of network multimedia teaching of English methods, the views of scholars and college teachers on the practical application methods of network multimedia teaching of English have changed from blind optimism to rational thinking [3]. While fully affirming the role and achievements of network multimedia teaching of English in realizing the optimization of English teaching process, 
the discussion on the negative and negative effects and improvement measures in the application of network multimedia teaching of English has become one of the hot issues concerned by scholars [4]. However, it is still common in colleges and universities to pay attention to the use of curriculum multimedia and ignore network multimedia teaching of English. The problem of lack of monitoring and effective management process of network multimedia teaching of English and effect has become very prominent. Therefore, it is necessary to adopt appropriate methods to evaluate the teaching quality according to the characteristics of network multimedia teaching of English, so as to lay a foundation for real-time monitoring and managing the process and effect of this teaching method [5].

The teaching quality evaluation index system based on Delphi method and analytic hierarchy process proposed by Cai et al. is to calculate the positive coefficient and Kendall harmony coefficient of relevant experts, combined with analytic hierarchy process to determine the weight of each index in the index system, so as to realize the evaluation of teaching quality and teaching quality. However, some indicators in this method have little impact on the evaluation results [6]; The education quality evaluation method based on interval valued fuzzy rough set proposed by $\mathrm{Xu}$ et al. Adopts the attribute reduction method of interval valued fuzzy rough set. In this method, the attribute importance is taken as the important heuristic information of attribute reduction, the indexes with insufficient importance are eliminated, and the reduced graduate education quality evaluation index system is obtained. On this basis, the weight of the evaluation index system is determined, and the comprehensive evaluation method of education quality to realize education quality evaluation is given. However, the importance of evaluation indicators in this method is different, which affects the final evaluation results [7]; The construction method of pre service teachers' technical pedagogical knowledge evaluation test proposed by Baier et al. mainly evaluates and tests teachers' pedagogical knowledge, constructs teachers' pedagogical knowledge evaluation system, and evaluates and tests teachers' pedagogical knowledge level, but too many redundant indicators have a certain impact on the evaluation results [8]; The construction method of the evaluation index system of ecological civilization education in Colleges and universities proposed by Ren et al. Mainly constructs the evaluation system by selecting relevant evaluation indexes to realize the evaluation of the level of ecological civilization education in Colleges and universities. However, this method has a large amount of calculation for the evaluation of teaching quality and increases the calculation time [9].

The evaluation of teachers' English network multimedia teaching quality is the value judgment of teaching results and teaching process [10]. Because the factors provided by colleges and universities to evaluate the quality of teachers' Network Multimedia English teaching are different, once too many evaluation factors are given, it is easy to increase the workload of teachers' Network Multimedia English teaching quality evaluation. Reducing the evaluation cost by reducing the data collection of some redundant influencing factors will undoubtedly help to establish a scientific evaluation system [11]. Rough set theory mainly studies incomplete and uncertain data. On the premise of maintaining the classification ability of information system, a better sub attribute set of information system attribute set is obtained through reduction [12]. The conditional information entropy attribute reduction algorithm combines the method of information theory, defines entropy and conditional entropy, and reduces the conditional attribute set inspired by the value of conditional information entropy. Through this algorithm, the effective reduction of English network multimedia teaching quality evaluation indexes is realized, the redundant indexes are removed, and the reduced key evaluation indexes are obtained. It greatly reduces the workload of evaluation and improves the scientificity of evaluation [13].

Based on the above analysis, this paper proposes an English network multimedia teaching quality evaluation method based on information entropy. The attribute reduction method of conditional information entropy is used to process the evaluation indexes of English network multimedia teaching quality. After simplification, the key evaluation indexes are obtained, and the evaluation model of English network multimedia teaching quality is constructed to evaluate the network multimedia English teaching quality of different teachers. This method reduces the redundant indicators, obtains the reduced key evaluation indicators, reduces a certain amount of evaluation calculation, provides a basis for colleges and universities to accurately analyze the English network multimedia teaching quality of different teachers, and is convenient for colleges and universities to improve the overall level of English network multimedia teaching.

\section{Evaluation method for network multimedia teaching quality of English}

\subsection{Selection of basic evaluation indexes}

Considering the teaching characteristics of network multimedia English course, through many discussions with students, teachers and relevant managers, 29 basic evaluation indexes of network multimedia teaching quality of English are finally selected, as shown in Table 1.

Among the above selected basic evaluation indexes of network multimedia teaching quality of English, the importance of each indicator is different. Some indexes have little impact on the evaluation results and can be regarded as redundant indexes. These redundant evaluation indexes increase the evaluation workload of network multimedia teaching quality of English. In order to effectively solve this problem, on the premise of not 
affecting the evaluation results of network multimedia teaching quality of English, according to the importance of each evaluation index to the evaluation results, a group of evaluation index combinations with greater importance to the evaluation results should be selected, so as to simplify the evaluation system for network multimedia teaching quality of English and reduce the amount of calculation of the whole network multimedia teaching quality evaluation of English, saving time and space [14]. Here, by using the concept of conditional information entropy and introducing a new attribute reduction method, the evaluation indexes in the network multimedia teaching quality evaluation of English are reduced [15], some redundant evaluation indexes are removed, the overall evaluation process of network multimedia teaching quality of English is simplified, the evaluation workload is reduced, and then the management of network multimedia teaching of English is simplified. The specific process is as follows.

Table 1. Basic evaluation indexes of network multimedia teaching quality of English

\begin{tabular}{|c|c|c|}
\hline Level indexes $(\mathrm{A})$ & The secondary indexes(B) & Level 3 indexes $(\mathrm{C})$ \\
\hline \multirow{8}{*}{$\begin{array}{l}\text { Multimedia English } \\
\text { classroom teaching } \\
\text { effect(A1) }\end{array}$} & \multirow{2}{*}{ Ability training(B1) } & Innovative thinking ability(C11) \\
\hline & & Ability to analyze and solve practical problems(C12) \\
\hline & \multirow{6}{*}{ Knowledge(B2) } & $\begin{array}{l}\text { Supplementary learning materials and the expansion of } \\
\text { knowledge }(\mathrm{C} 21)\end{array}$ \\
\hline & & The cultivation of interest in learning(C22) \\
\hline & & Practice in time and in various ways (C23) \\
\hline & & Knowledge teaching satisfies the internal logic of the course(C24) \\
\hline & & The key points are explained thoroughly $(\mathrm{C} 25)$ \\
\hline & & The learning environment of multimedia English classroom(C31) \\
\hline \multirow{9}{*}{$\begin{array}{c}\text { Multimedia English } \\
\text { classroom teaching } \\
\text { process(A2) }\end{array}$} & \multirow{5}{*}{ Equipment usage(B3) } & Teaching operation proficiency (C32) \\
\hline & & Audio and video playback clarity and fluency(C33) \\
\hline & & Clarity of teaching equipment(C34) \\
\hline & & The classroom atmosphere $(\mathrm{C} 41)$ \\
\hline & & Ability to deal with special situations in class $(\mathrm{C} 42)$ \\
\hline & \multirow{4}{*}{$\begin{array}{l}\text { Classroom teaching } \\
\text { control(B4) }\end{array}$} & Teaching rhythm control(C43) \\
\hline & & Student interaction(C44) \\
\hline & & Student and teacher interaction(C45) \\
\hline & & Update of courseware $(\mathrm{C} 46)$ \\
\hline \multirow{12}{*}{$\begin{array}{l}\text { The creation quality } \\
\text { of multimedia } \\
\text { English courseware } \\
\text { itself(A3) }\end{array}$} & \multirow{4}{*}{$\begin{array}{l}\text { The technical } \\
\text { requirements(B5) }\end{array}$} & No innovation according to courseware(C47) \\
\hline & & Easy to operate, accurate link(C51) \\
\hline & & Reasonable combination of sound, video, animation and text(C52) \\
\hline & & Video and audio are clear(C61) \\
\hline & \multirow[t]{5}{*}{ Art requires(B6) } & Moderate writing, easy to record(C62) \\
\hline & & The page is clear and well laid out(C63) \\
\hline & & Combine with actual cases $(\mathrm{C} 71)$ \\
\hline & & Explain thoroughly $(\mathrm{C} 72)$ \\
\hline & & Clear priorities, simple and proper(C73) \\
\hline & Teaching requirements(B7) & The teaching content is rich and informative $(\mathrm{C} 74)$ \\
\hline & & Reflect the characteristics of professional courses $(\mathrm{C} 75)$ \\
\hline & & $\begin{array}{l}\text { Consistent with the teaching objectives and contents of professional } \\
\text { courses(C76) }\end{array}$ \\
\hline
\end{tabular}

results [16]. Let an information system be represented by

\subsection{Redundancy evaluation index reduction based on conditional information entropy attribute reduction}

By introducing a conditional information entropy attribute reduction method, the redundancy reduction is implemented for the evaluation indexes of network multimedia teaching quality of English, and some redundant evaluation indexes are removed through the attribute importance value, so as to reduce the subjective impact of the weight distribution of the evaluation indexes and ensure the objectivity and rationality of the evaluation four tuples $S=(U, A=C \bigcup D, V, f)$, where $U=\left\{x_{1}, x_{2}, \ldots, x_{k}\right\}$ is the universe; A represents attribute set, including conditional attribute set $\mathrm{C}$ and decision attribute set D; $V=\bigcup_{a \in A} V_{a}$, where $V_{a}$ is the value range of attribute a; $f: U \times C \cup D \rightarrow V$. Any attribute set on $U$ can be regarded as a random variable on U.

Definition 1. The partition of attribute set $P$ and attribute set $\mathrm{Q}$ on $\mathrm{U}$ is expressed as $X=\left\{X_{1}, X_{2}, \ldots, X_{n}\right\}$ and $Y=\left\{Y_{1}, Y_{2}, \ldots, Y_{m}\right\}$ 
respectively. The partition of $\mathrm{P}$ and $\mathrm{Q}$ on $\mathrm{U}$, and the subset probability distribution is expressed as:

$$
\left\{\begin{array}{c}
{[X: p]=\left[\begin{array}{cccc}
X_{1} & X_{2} & \cdots & X_{n} \\
p\left(X_{1}\right) & p\left(X_{2}\right) & \cdots & p\left(X_{n}\right)
\end{array}\right]} \\
{[Y: p]=\left[\begin{array}{cccc}
Y_{1} & Y_{2} & \cdots & Y_{m} \\
p\left(Y_{1}\right) & p\left(Y_{2}\right) & \cdots & p\left(Y_{m}\right)
\end{array}\right]} \\
p\left(X_{i}\right)=\frac{\left|X_{i}\right|}{|U|} i=1,2, \ldots, n
\end{array}\right.
$$

Where

$$
p\left(Y_{j}\right)=\frac{\left|Y_{j}\right|}{|U|} j=1,2, \ldots, m
$$

Definition 2: the entropy $H(P)$ of attribute set $\mathrm{P}$ is defined as:

$$
H(P)=-\sum_{i=1}^{n} p\left(X_{i}\right) \log \left(p\left(X_{i}\right)\right)
$$

Definition 3: the conditional information entropy $H(Q \mid P)$ defined as: of attribute set $\mathrm{Q}$ relative to attribute set $\mathrm{P}$ is

$$
H(Q \mid P)=-\sum_{i=1}^{n} p\left(X_{i}\right) \sum_{j=1}^{m} p\left(Y_{j} \mid X_{i}\right) \log \left(p\left(Y_{j} \mid X_{i}\right)\right)
$$

Where $P\left(Y_{j} \mid X_{i}\right)=\frac{\left|Y_{j} \cap X_{i}\right|}{\left|X_{i}\right|}, i=1,2, \cdots, n$, $j=1,2, \ldots, m$

Definition 4: if $R \subseteq C$, the attribute importance $S G F(a, R, D)$ of any attribute a in R relative to decision attribute $\mathrm{D}$ is defined as:

$$
S G F(a, R, D)=H(D \mid R-\{a\})-H(D \mid R)
$$

The value of attribute importance $\operatorname{SGF}(a, R, D)$ is directly related to the importance of attribute a to decision attribute $\mathrm{D}$. the larger the value is, the more important element a is to D in R. $\operatorname{SGF}(a, R, D)$ can be used as heuristic information to find better or suboptimal reduction, so as to reduce spatial complexity.

\section{Table 2. Evaluation indexes after attribute reduction of conditional information entropy}

The conditional information entropy attribute reduction method is applied to the evaluation index reduction in this paper. Taking the conditional information entropy as the heuristic information, the basic evaluation indexes in the previous section are reduced and a new evaluation index system is established, which belongs to a heuristic attribute reduction algorithm [17]. The index reduction process of the algorithm is as follows:

(1) Input: the known basic evaluation system of network multimedia teaching quality of English, recorded as $S=(U, A=C \cup D, V, f)$; Record $\mathrm{R}$ as the reduction result of the evaluation index, and initialize $R=C$;

(2) s1: calculate the value of $\mathrm{C}$ positive field $P O S_{C} D$ of $\mathrm{D}$ in $\mathrm{S}$ and the value of conditional entropy $H(D \mid a)$ of $\mathrm{D}$ with respect to any evaluation index $\mathrm{a}$;

(3) s2: for any evaluation index a in R, calculate the importance $S G F(a, R, D)$ of a to decision attribute D;

(4) s3: sort the evaluation index $a_{i}$ according to the value of $\operatorname{SGF}(a, R, D)$ from small to large. If the value of $\operatorname{SGF}(a, R, D)$ is the same, sort $a_{i}$ according to the value of $H\left(D \mid a_{i}\right)$ from large to small;

(5) s4: compare $P O S_{R-\left\{a_{i}\right\}} D$ and $P O S_{C} D$ according to the evaluation index set $\left\{a_{i}\right\}$ arranged in s3. If they are equal, the evaluation index $a_{i}$ is redundant, $R=R-\left\{a_{i}\right\}$, the cycle ends and goes to s2; If all elements in $\left\{a_{i}\right\}$ do not satisfy

$$
P O S_{R-\left\{a_{i}\right\}} D=P O S_{C} D \text {, the algorithm ends; }
$$

(6) Output: a better evaluation index reduction result $\mathrm{R}$ of the original basic evaluation system for network multimedia teaching quality of English.

Through the above reduction process, the basic evaluation indexes in Table 1 are reduced to obtain the reduced evaluation indexes for network multimedia teaching quality of English, as shown in Table 2.

\begin{tabular}{cc}
\hline Level indexes $(\mathrm{A})$ & The secondary indexes(B) \\
\hline $\begin{array}{c}\text { Multimedia English } \\
\text { classroom teaching } \\
\text { effect(A1) }\end{array}$ & Ability training(B1) \\
& Knowledge(B2)
\end{tabular}

Level 3 indexes $(\mathrm{C})$

Innovative thinking ability $(\mathrm{C} 11)$

Ability to analyze and solve practical problems $(\mathrm{C} 12)$ Supplementary learning materials and the expansion of knowledge(C21)

Practice in time and in various ways(C23) 


\section{Multimedia English classroom teaching process $(\mathrm{A} 2)$}

The creation quality of multimedia English courseware itself(A3)

\section{Classroom teaching control(B4)}

The technical

requirements(B5)

Teaching requirements(B7)
The key points are explained thoroughly $(\mathrm{C} 25)$

Ability to deal with special situations in class(C42) Student interaction(C44)

Student and teacher interaction(C45) Update of courseware $(\mathrm{C} 46)$

Easy to operate, accurate link(C51)

Reasonable combination of sound, video, animation and text(C52) Combine with actual cases $(\mathrm{C} 71)$

Clear priorities, simple and proper(C73)

The teaching content is rich and informative(C74)

Reflect the characteristics of professional courses $(C 75)$

the established model is used to solve the problem of dynamic distribution of multi-level evaluation index weight, so as to realize the teacher's evaluation of network multimedia teaching quality of English [18]. The establishment process of the evaluation model is as follows:

(1) Teacher's individual evaluation vector $R^{\prime}$. Taking a teacher of network multimedia English as an example, the school collects the evaluation forms of 15 teaching quality evaluation indexes from the students in the class taught by the English teacher through the network, as shown in Table 3.
Suppose that the school is going to evaluate the teaching quality of $\mathrm{m}$ teachers participating in network multimedia teaching of English, in which the main body participating in the evaluation is students. Based on the above reduced 15 evaluation indexes, an evaluation model for network multimedia teaching quality of English is established, and

Table 3. Network multimedia English teaching student evaluation questionnaire

\begin{tabular}{|c|c|c|c|c|c|c|}
\hline \multirow[b]{2}{*}{ Evaluate indexes and factor sets } & \multicolumn{5}{|c|}{ Assessment language and assessment set } & \multirow[b]{2}{*}{$\begin{array}{c}\text { Very bad } \\
\text { e5 }\end{array}$} \\
\hline & & $\begin{array}{c}\text { Very good } \\
\text { e1 }\end{array}$ & $\begin{array}{c}\text { Good } \\
\text { e2 }\end{array}$ & $\begin{array}{c}\text { General } \\
\text { e3 }\end{array}$ & $\begin{array}{c}\text { Bad } \\
\text { e4 }\end{array}$ & \\
\hline Innovative thinking ability & $\mathrm{c} 1$ & b11 & & $\ldots$ & $\ldots$ & $\ldots$ \\
\hline Ability to analyze and solve practical problems & c2 & $\ldots$ & b22 & $\ldots$ & $\ldots$ & $\ldots$ \\
\hline Supplementary learning materials and the expansion of knowledge & c3 & $\ldots$ & b33 & $\ldots$ & $\ldots$ & $\ldots$ \\
\hline Practice in time and in various ways & c4 & $\cdots$ & $\ldots$ & b44 & $\cdots$ & $\cdots$ \\
\hline The key points are explained thoroughly & c5 & $\cdots$ & $\cdots$ & $\ldots$ & $\cdots$ & $\cdots$ \\
\hline Ability to deal with special situations in class & c6 & $\cdots$ & $\cdots$ & $\cdots$ & $\cdots$ & $\cdots$ \\
\hline Student interaction & c7 & $\ldots$ & $\ldots$ & $\ldots$ & $\ldots$ & $\ldots$ \\
\hline Student and teacher interaction & c8 & $\ldots$ & $\ldots$ & $\ldots$ & $\ldots$ & $\ldots$ \\
\hline Update of courseware & c9 & $\ldots$ & $\ldots$ & $\ldots$ & $\ldots$ & $\ldots$ \\
\hline Easy to operate, accurate link & c10 & $\ldots$ & $\ldots$ & $\ldots$ & $\ldots$ & $\ldots$ \\
\hline Reasonable combination of sound, video, animation and text & c11 & $\ldots$ & $\ldots$ & $\ldots$ & $\ldots$ & $\ldots$ \\
\hline Combine with actual cases & c12 & $\ldots$ & $\ldots$ & $\ldots$ & $\ldots$ & $\ldots$ \\
\hline Clear priorities, simple and proper & c13 & $\ldots$ & $\ldots$ & $\ldots$ & $\ldots$ & $\ldots$ \\
\hline The teaching content is rich and informative & c14 & $\ldots$ & $\ldots$ & $\ldots$ & $\ldots$ & $\ldots$ \\
\hline Reflect the characteristics of professional courses & c15 & $\ldots$ & $\ldots$ & $\ldots$ & $\ldots$ & b55 \\
\hline
\end{tabular}

After collecting and summarizing the teacher's evaluation questionnaires from all students, the teacher's evaluation matrix is as follows:

$$
B=\left[\begin{array}{cccc}
b_{11} & b_{12} & \cdots & b_{15} \\
b_{21} & b_{22} & \cdots & b_{25} \\
\cdots & \cdots & \cdots & \cdots \\
b_{151} & b_{152} & \cdots & b_{155}
\end{array}\right]
$$

defined. The corresponding quantization matrix is

$$
G=\{5,4,3,2,1\} \text {, }
$$$$
R^{\prime}=\left\{r_{i}^{\prime}\right\} \text {, where } i \in[1,15] \text {, and has: }
$$

$$
r_{i}^{\prime}=\frac{1}{n} \sum_{j=1}^{5} g j \times b_{i j}
$$

(2) Evaluation matrix E. By calculating the individual evaluation vectors of $\mathrm{m}$ English teachers, the evaluation indexes and evaluation objects are composed of $\mathrm{m}$ individual evaluation vectors. Table 4 shows the details.

The evaluation matrix obtained from Table 4 is:
Where, $b_{i j}$ represents the evaluation value (i.e. the number of votes) of $n$ students on the evaluation index $i$ in evaluation set $\mathrm{j}$ of the teacher. Here, the evaluation set matrix \{very good, good, general, bad, very bad $\}$ is 


$$
E=\left[\begin{array}{cccc}
e_{11} & e_{12} & \cdots & e_{115} \\
e_{21} & e_{22} & \cdots & e_{215} \\
\cdots & \cdots & \cdots & \cdots \\
e_{m 1} & e_{m 2} & \cdots & e_{m 15}
\end{array}\right]
$$

Where, ${ }^{e_{i j}}$ represents the $\mathrm{j}$-th evaluation index for the i-th teacher, that is, the value of ${ }^{\prime}{ }_{j}^{\prime}$. After standardizing this matrix, we can get:

$$
E^{\prime}=\left(e_{i j}^{\prime}\right)_{m \times 15}
$$

Under the above assignment rules, the evaluation index can be regarded as a benefit index, so it can make:

$$
e_{i j}^{\prime}=\left(e_{i j}-\min _{i}\left\{e_{i j}\right\}\right) /\left(\max _{i}\left\{e_{i j}\right\}-\min _{i}\left\{e_{i j}\right\}\right)
$$

\begin{tabular}{|c|c|c|c|c|c|}
\hline \multicolumn{2}{|c|}{ Evaluation object } & $\mathrm{k} 1$ & k2 & $\ldots$ & $\mathrm{km}$ \\
\hline \multirow{15}{*}{$\begin{array}{c}\text { Evaluation } \\
\text { indexes }\end{array}$} & $\mathrm{c} 1$ & $\mathrm{e} 11$ & e21 & $\ldots$ & em1 \\
\hline & c2 & e12 & e22 & $\ldots$ & em2 \\
\hline & c3 & $\ldots$ & $\ldots$ & $\ldots$ & $\ldots$ \\
\hline & c4 & $\ldots$ & $\ldots$ & $\ldots$ & $\ldots$ \\
\hline & c5 & $\ldots$ & $\ldots$ & $\ldots$ & $\ldots$ \\
\hline & c6 & $\ldots$ & $\ldots$ & $\ldots$ & $\ldots$ \\
\hline & c7 & $\ldots$ & $\ldots$ & $\ldots$ & $\ldots$ \\
\hline & $\mathrm{c} 8$ & $\ldots$ & $\ldots$ & $\ldots$ & $\ldots$ \\
\hline & c9 & $\ldots$ & $\ldots$ & $\ldots$ & $\ldots$ \\
\hline & c10 & $\ldots$ & $\ldots$ & $\ldots$ & $\ldots$ \\
\hline & c11 & $\ldots$ & $\ldots$ & $\ldots$ & $\ldots$ \\
\hline & c12 & $\ldots$ & $\ldots$ & $\ldots$ & $\ldots$ \\
\hline & c13 & $\ldots$ & $\ldots$ & $\ldots$ & $\ldots$ \\
\hline & c14 & $\ldots$ & $\ldots$ & $\ldots$ & $\ldots$ \\
\hline & c15 & e115 & e215 & $\ldots$ & em15 \\
\hline
\end{tabular}

Table 4. Evaluation indexes and evaluation objects

(3) Determine the weight $\mathrm{W}$ of each evaluation index. When evaluating teachers' network multimedia teaching quality of English, we should not only pay attention to the importance of the evaluation index itself, but also pay attention to whether the evaluation index can effectively reflect the differences between different teachers [19]. For an evaluation index, the greater the difference of evaluation index values among participating teachers is, the greater its role in comprehensive evaluation is; If the evaluation index values are all equal, the evaluation index does not work in the comprehensive evaluation and does not provide any useful information. In information theory, information entropy is a measure of system disorder. The greater the index value variation of an evaluation index is, the smaller the information entropy is, the greater the amount of information provided by the evaluation index is, and the greater the weight of the evaluation index is; On the contrary, the weight of the evaluation index is smaller [20]. Next, we will calculate the entropy weight of each evaluation index by using the concept of entropy weight according to the variation degree of index value of each evaluation index.

The entropy of the $\mathrm{j}$-th evaluation index is defined as:

$$
H_{i}^{\prime}=\sum_{i=1}^{15}-q_{i j} \ln \left(q_{i j}\right)
$$

Where, $q_{i j}=e_{i j}^{\prime} / \sum_{i=1}^{15} e_{i j}^{\prime}$

The entropy weight of the $\mathrm{j}$-th evaluation index is defined as:

$$
W_{i}=\left(1-H_{j}^{\prime}\right) / \sum_{i=1}^{15}\left(1-H_{j}^{\prime}\right)
$$

(4) Comprehensive evaluation index L. The distance between the evaluation value obtained by the standardization of the evaluation matrix and the ideal point is used to sort the network multimedia English teachers in real time, and the evaluation result queue is determined according to the distance, that is, the shorter the distance is, the better the results are, and the longer the distance is, the worse the results are. If $Q^{\prime}=(1,1, \ldots, 1)$ is taken as the ideal point here, the distance between teacher $i$ and the ideal point can be defined as:

$$
L_{i}=\sqrt{\sum_{j=1}^{15} W_{j}^{2}\left(1-q_{i j}\right)^{2}}
$$

When queuing the results, if two or more distance values are equal, the results can be sorted according to the importance of the evaluation index.

\section{Analysis of experimental results}

\subsection{Experimental setup}

In order to test the practical applicability of the proposed method, six English teachers who have been teaching for 10 years or more are randomly selected from a university as the experimental objects. The proposed method is used to evaluate the network multimedia teaching quality of English of the selected teachers from 2010 to 2019, and analyze the changes of teaching quality of each teacher in 10 years. Through the analysis on the evaluation results of teaching quality, the practical application effect of the method in this paper is tested. The selected six network multimedia English teachers are numbered K1 K6, including two male teachers and four female teachers, aged from 38 to 47 .

\subsection{Analysis of students' teaching evaluation results}

Firstly, taking 2019 as an example, this paper uses the proposed method to evaluate the network multimedia 
teaching quality of English of six teachers in 2019. The specific evaluation process and results are as follows.

600 students who have participated in 6 teachers' network multimedia English teaching are randomly selected from different grades of the experimental

\begin{tabular}{|c|c|c|c|c|c|c|c|c|c|c|c|c|c|c|c|c|}
\hline $\begin{array}{c}\text { Teacher's } \\
\text { number }\end{array}$ & $\begin{array}{c}\text { Evaluation } \\
\text { indexes }\end{array}$ & $\mathrm{c} 1$ & c2 & c3 & c4 & c5 & $\mathrm{c} 6$ & c7 & c8 & $c 9$ & c10 & c11 & c12 & c13 & c14 & c15 \\
\hline \multirow{5}{*}{ k1 } & $\mathrm{e} 1$ & 255 & 278 & 359 & 224 & 328 & 428 & 270 & 248 & 408 & 349 & 275 & 280 & 288 & 234 & 369 \\
\hline & e2 & 296 & 247 & 188 & 311 & 176 & 137 & 285 & 283 & 157 & 198 & 276 & 275 & 257 & 301 & 188 \\
\hline & e3 & 33 & 55 & 33 & 50 & 76 & 20 & 27 & 48 & 21 & 30 & 23 & 28 & 35 & 45 & 24 \\
\hline & e4 & 14 & 17 & 18 & 13 & 18 & 13 & 15 & 19 & 14 & 22 & 24 & 17 & 18 & 19 & 16 \\
\hline & e5 & 2 & 3 & 2 & 2 & 2 & 2 & 3 & 2 & 0 & 1 & 2 & 0 & 2 & 1 & 3 \\
\hline \multirow{5}{*}{ k2 } & e1 & 245 & 269 & 252 & 280 & 365 & 321 & 266 & 222 & 237 & 281 & 315 & 289 & 306 & 269 & 248 \\
\hline & e2 & 293 & 252 & 291 & 284 & 149 & 244 & 284 & 294 & 286 & 249 & 246 & 258 & 252 & 261 & 282 \\
\hline & e3 & 44 & 58 & 36 & 21 & 63 & 20 & 30 & 59 & 55 & 48 & 29 & 30 & 28 & 52 & 50 \\
\hline & e4 & 16 & 18 & 19 & 13 & 20 & 13 & 16 & 21 & 21 & 22 & 9 & 20 & 10 & 16 & 20 \\
\hline & e5 & 2 & 3 & 2 & 2 & 3 & 2 & 4 & 4 & 1 & 0 & 1 & 3 & 4 & 2 & 0 \\
\hline \multirow{5}{*}{ k3 } & e1 & 225 & 133 & 351 & 275 & 365 & 413 & 240 & 220 & 255 & 403 & 385 & 295 & 341 & 230 & 153 \\
\hline & e2 & 294 & 352 & 185 & 288 & 149 & 152 & 284 & 281 & 269 & 162 & 139 & 268 & 195 & 291 & 332 \\
\hline & e3 & 62 & 96 & 39 & 22 & 58 & 20 & 55 & 68 & 45 & 22 & 48 & 25 & 31 & 48 & 76 \\
\hline & e4 & 17 & 16 & 23 & 13 & 24 & 13 & 16 & 24 & 28 & 10 & 26 & 11 & 33 & 31 & 35 \\
\hline & e5 & 2 & 3 & 2 & 2 & 4 & 2 & 5 & 7 & 3 & 3 & 2 & 1 & 0 & 0 & 4 \\
\hline \multirow{5}{*}{$\mathrm{k} 4$} & $\mathrm{e} 1$ & 175 & 143 & 351 & 269 & 352 & 391 & 246 & 215 & 235 & 266 & 371 & 362 & 279 & 371 & 163 \\
\hline & e2 & 344 & 354 & 181 & 294 & 149 & 174 & 284 & 275 & 265 & 264 & 184 & 139 & 284 & 171 & 334 \\
\hline & e3 & 62 & 81 & 41 & 22 & 68 & 20 & 49 & 72 & 62 & 40 & 30 & 58 & 20 & 31 & 71 \\
\hline & e4 & 17 & 18 & 23 & 13 & 27 & 13 & 15 & 29 & 38 & 25 & 9 & 38 & 17 & 24 & 27 \\
\hline & e5 & 2 & 4 & 4 & 2 & 4 & 2 & 6 & 9 & 0 & 5 & 6 & 3 & 0 & 3 & 5 \\
\hline \multirow{5}{*}{ k5 } & e1 & 326 & 278 & 331 & 418 & 230 & 247 & 168 & 260 & 333 & 345 & 378 & 352 & 298 & 341 & 214 \\
\hline & e2 & 223 & 199 & 206 & 147 & 270 & 282 & 329 & 299 & 229 & 169 & 176 & 153 & 286 & 181 & 275 \\
\hline & e3 & 23 & 100 & 45 & 22 & 60 & 45 & 70 & 26 & 25 & 66 & 29 & 60 & 5 & 42 & 69 \\
\hline & e4 & 18 & 8 & 9 & 13 & 40 & 25 & 28 & 13 & 6 & 17 & 11 & 31 & 2 & 23 & 32 \\
\hline & e5 & 10 & 15 & 9 & 0 & 0 & 1 & 5 & 2 & 7 & 3 & 6 & 4 & 9 & 13 & 10 \\
\hline \multirow{5}{*}{ k6 } & $\mathrm{e} 1$ & 266 & 225 & 285 & 341 & 336 & 298 & 256 & 279 & 316 & 185 & 288 & 366 & 343 & 258 & 327 \\
\hline & e2 & 264 & 265 & 243 & 196 & 213 & 276 & 247 & 261 & 217 & 316 & 189 & 152 & 219 & 306 & 241 \\
\hline & e3 & 40 & 62 & 33 & 52 & 28 & 11 & 55 & 38 & 43 & 76 & 101 & 38 & 23 & 22 & 18 \\
\hline & e4 & 25 & 40 & 39 & 9 & 13 & 6 & 35 & 18 & 18 & 23 & 11 & 39 & 8 & 9 & 12 \\
\hline & e5 & 5 & 8 & 0 & 2 & 10 & 9 & 7 & 4 & 6 & 0 & 11 & 5 & 7 & 5 & 2 \\
\hline
\end{tabular}

Through this method, the standardized evaluation matrix is obtained by using the data in Table 5, and the entropy and weight of each evaluation index are obtained, as shown in Table 6.

From table 6, we can see that the weights of c5, c2 and c1 are relatively high, indicating that the three aspects of thorough explanation of key knowledge points, ability to analyze and solve practical problems and ability of innovative thinking have a higher impact on the quality of network multimedia teaching of English; Secondly, there are three evaluation indexes: $\mathrm{c} 3, \mathrm{c} 4$ and $\mathrm{c} 12$, namely, the supplement of auxiliary learning materials and the expansion of knowledge, the timeliness and diversity of practice methods, and the combination of actual cases; the weights of c10, c11, c13, c15 and c9 are relatively the lowest, all lower than 0.05, indicating that the five aspects of convenient operation and accurate link, reasonable combination of sound, image, animation and text, clear primary and secondary, appropriate complexity and simplicity, reflecting the characteristics of professional courses and courseware update have relatively little university as the main body of teaching evaluation. After the 6 teachers are evaluated through the network, the statistical results of students' teaching evaluation are shown in Table 5.

impact on the quality of network multimedia teaching of English.

Table 6. Entropy and weight calculation results of each evaluation index

\begin{tabular}{ccc}
\hline $\begin{array}{c}\text { Evaluation } \\
\text { indexes }\end{array}$ & Entropy(Hi) & $\begin{array}{c}\text { The } \\
\text { weight(Wi) }\end{array}$ \\
\hline c1 & 0.796 & 0.095 \\
c2 & 0.778 & 0.101 \\
c3 & 0.826 & 0.085 \\
c4 & 0.835 & 0.082 \\
c5 & 0.766 & 0.105 \\
c6 & 0.883 & 0.066 \\
c7 & 0.904 & 0.059 \\
c8 & 0.892 & 0.063 \\
c9 & 0.940 & 0.047 \\
c10 & 0.988 & 0.031 \\
c11 & 0.973 & 0.036 \\
c12 & 0.862 & 0.073 \\
c13 & 0.955 & 0.042
\end{tabular}




$\begin{array}{lll}c 14 & 0.877 & 0.068 \\ c 15 & 0.940 & 0.047\end{array}$

From the above, in order to improve the quality of teachers' network multimedia teaching of English, we need to focus on improving teachers' ability to explain key knowledge points thoroughly, analyze and solve practical problems and innovative thinking, so as to further improve the English teaching level of colleges and universities.

\subsection{Comprehensive distance value of teachers from 2010 to 2019}

According to the above results, the comprehensive distance value from each index vector of 6 teachers to the ideal point, i.e. the value of L1 to L6, is obtained through the proposed method, as shown in Figure 1.

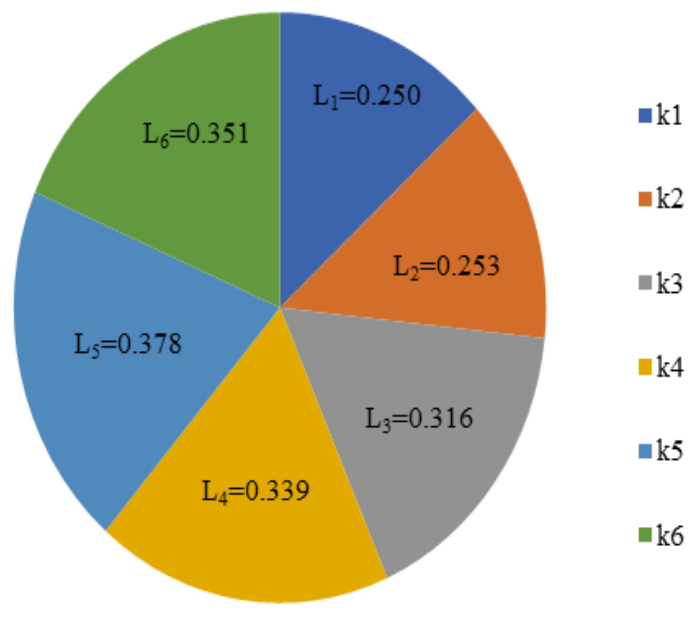

Figure 1. The comprehensive value of the distance between the index vector of 6 teachers and the ideal point

It can be seen from Figure 1 that the comprehensive value of the distance between each index vector and the ideal point of the six teachers is L5-L6-L4-L3-L2-L1 from high to low. It can be seen that the comprehensive value of the distance between each index vector of teacher $\mathrm{k} 5$ and the ideal point is the highest, followed by teachers $\mathrm{k} 6, \mathrm{k} 4, \mathrm{k} 3$ and $\mathrm{k} 2$, and the teacher with the lowest comprehensive value of distance is $\mathrm{k} 1$, indicating that the final comprehensive evaluation result of teacher $\mathrm{k} 1$ is the best. The teacher's network multimedia teaching quality of English is the highest, followed by teachers k2, k3, k4 and k6. Relatively speaking, the teacher $\mathrm{k} 5$ has the lowest network multimedia teaching quality of English.

In order to further test the evaluation effect of the proposed method, the network multimedia English teaching quality of the selected 6 teachers from 2010 to
2018 is evaluated according to the above process, and the changes of network multimedia English teaching quality of each teacher in 10 years are comprehensively analyzed according to the evaluation results obtained by the proposed method. The comprehensive statistical results of the distance between the evaluation index vector for network multimedia teaching quality of English and the ideal point of 6 teachers from 2010 to 2019 are shown in Figure 2.

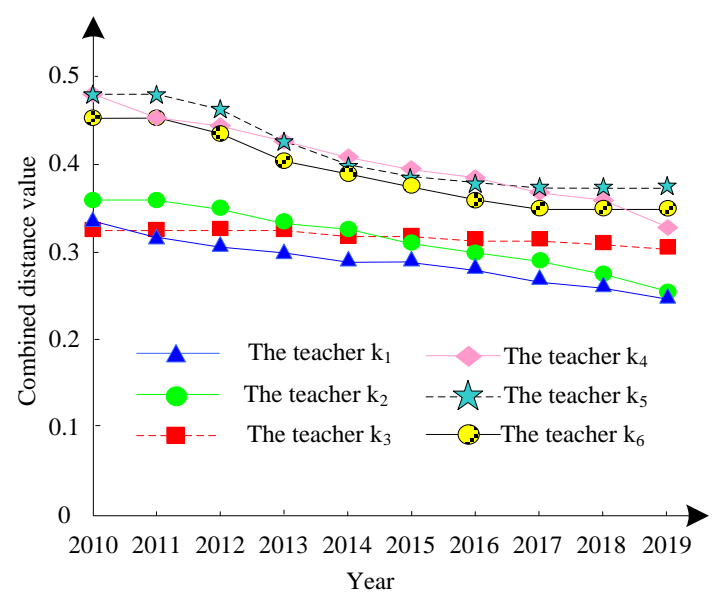

Figure 2. Change of comprehensive distance values of teachers from 2010 to 2019

It can be seen from Figure 2 that the comprehensive value of the distance between the evaluation index vector and the ideal point of teacher $\mathrm{k} 3$ in the 10 years from 2010 to 2019 has no obvious change and is almost flat; The comprehensive value of the distance between the evaluation index vector and the ideal point of teachers $\mathrm{k} 1$ and $\mathrm{k} 2$ in the past 10 years shows a slow decreasing trend, and the overall change is between 0.8 and 1.2 ; the comprehensive value of the distance between the evaluation index vector and the ideal point of teachers $\mathrm{k} 4$ in the past 10 years shows a continuous downward trend, and the decline range is large. Compared with 2010, the comprehensive value of the distance in 2019 is decreased by 1.66; The comprehensive value of the distance between the evaluation index vector of teachers $\mathrm{k} 5$ and $\mathrm{k} 6$ and the ideal point shows a significant downward trend from 2011 to 2017 , and there is no change in other years. It can be seen that there is no significant change in the quality of network multimedia English teaching for teachers k3 from 2010 to 2019, the quality of network multimedia English teaching for teachers $\mathrm{k} 1$ and $\mathrm{k} 2$ continues to improve, the quality of network multimedia English teaching for teachers $\mathrm{k} 4$ is the most significant, and the quality of network multimedia English teaching for teachers $\mathrm{k} 5$ and $\mathrm{k} 6$ shows no sign of improvement from 2010 to 2011. It has been significantly improved from 2011 to 2017, and the teaching quality in 2017 has 
been maintained from 2017 to 2019 , with no signs of improvement.

\subsection{Key factors affecting teachers' Network Multimedia English teaching quality}

In order to analyze the key factors affecting the quality of teachers' network multimedia teaching of English, this paper evaluates and analyzes teachers from three aspects: teaching effect of multimedia English class, teaching process of multimedia English class and courseware creation quality of multimedia English class. Among them, the teaching effect of multimedia English class includes $\mathrm{c} 1 \sim \mathrm{c} 5$ indexes. The teaching process of multimedia English class includes c6 c9 indexes, and the courseware creation quality of multimedia English class includes $\mathrm{c} 10 \sim \mathrm{c} 15$ indexes. The evaluation results are shown in Figure 3.

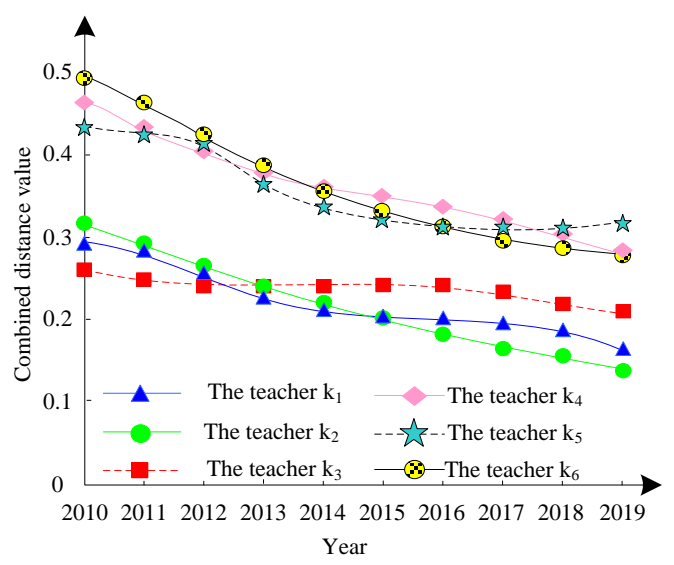

(a)Results and trends of multimedia English classroom teaching effectiveness evaluation

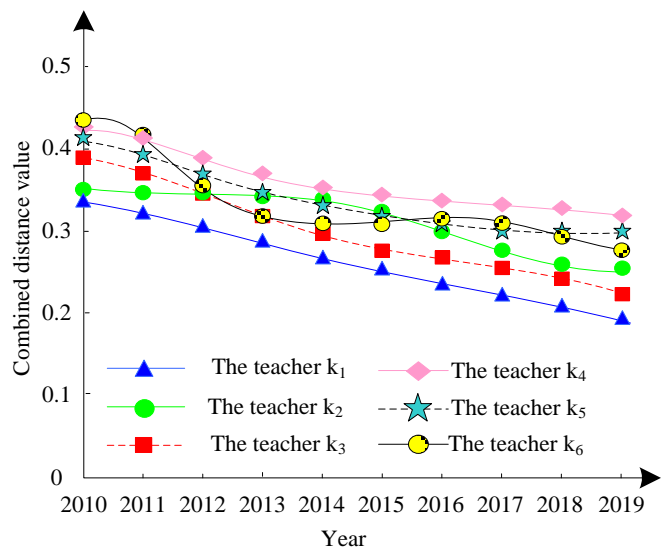

(b)Results and trends of multimedia English classroom teaching process assessment

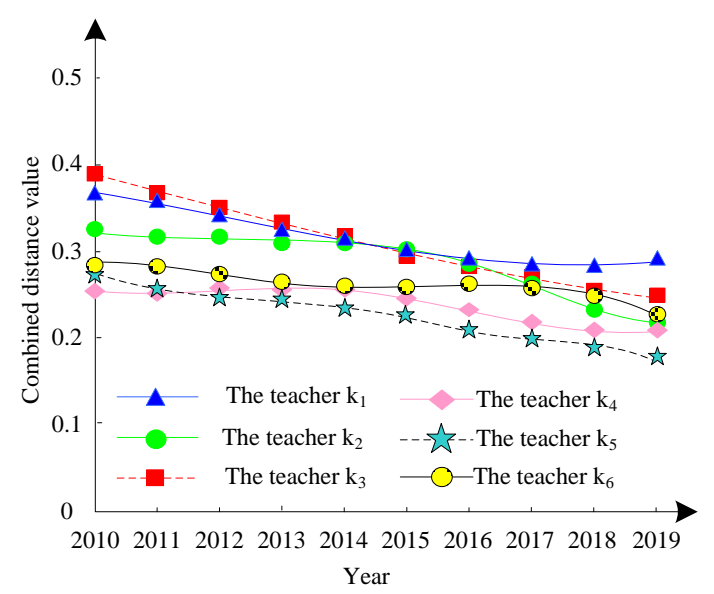

(c)Evaluation results and trends of multimedia English courseware creation quality Figure 3. Evaluation results and trends of teachers
in three aspects

As can be seen from Figure 3, in terms of teaching effect of multimedia English class, the index comprehensive distance values of six teachers show a gradual downward trend, in which the downward trend of teacher $\mathrm{k} 3$ is not obvious, teachers $\mathrm{k} 1, \mathrm{k} 2$ and $\mathrm{k} 3$ perform better in this aspect, while teachers $\mathrm{k} 4, \mathrm{k} 5$ and $\mathrm{k} 6$ perform poorly; in terms of the teaching process of multimedia English class, the comprehensive distance values of the six teachers also show a downward trend, and the overall distance values are close; In terms of the courseware creation quality of multimedia English, the comprehensive index values of teachers $\mathrm{k} 2, \mathrm{k} 4$ and $\mathrm{k} 6$ have a slight upward trend, while the comprehensive index values of other teachers still show a downward trend, and in this regard, teachers $\mathrm{k} 4, \mathrm{k} 5$ and $\mathrm{k} 6$ are slightly better than teachers $\mathrm{k} 1, \mathrm{k} 2$ and $\mathrm{k} 3$. According to the comprehensive analysis, teachers $\mathrm{k} 4, \mathrm{k} 5$ and $\mathrm{k} 6$ perform slightly worse in the teaching effect of multimedia English class, so this aspect is the key factor affecting the quality of the three teachers' network multimedia teaching of English, and the weight of the indexes contained in this aspect is relatively high. Therefore, in the future network multimedia teaching of English, teachers $\mathrm{k} 4, \mathrm{k} 5$ and $\mathrm{k} 6$, should focus on improving the ability in this aspect; Teachers $\mathrm{k} 1, \mathrm{k} 2$ and $\mathrm{k} 3$ are slightly poor in the courseware creation quality of mltimedia English, so this is the key factor affecting the quality of network multimedia teaching of English of these three teachers. Therefore, in the future network multimedia teaching of English, teachers k1, k2 and k3 should appropriately improve the courseware creation quality of Multimedia English and further improve the overall quality of network multimedia teaching of English. 


\section{Discussion}

This paper studies the online multimedia English teaching quality evaluation method based on information entropy, and applies this method to the teaching quality evaluation of 6 online multimedia English teachers in a university. Through practical application, the following analysis results are obtained:.

(1) The key knowledge points are explained thoroughly, the ability to analyze and solve practical problems and the ability of innovative thinking have the highest weight, which has the greatest impact on the quality of English network multimedia teaching. It is necessary to focus on improving the above three abilities of teachers;

(2) The comprehensive value of the distance between each index vector and the ideal point of the six teachers from high to low is L5 > L6 > L4 > L3 > L2 > L1. Therefore, the final comprehensive evaluation result of K1 teachers' English network multimedia teaching quality is the best. The teacher's English network multimedia teaching quality is the highest;

(3) From 2010 to 2019, the online multimedia English teaching quality of $\mathrm{K} 1$ and $\mathrm{K} 2$ teachers continued to improve, and there was no significant change in the online multimedia English teaching quality of $\mathrm{K} 3$ teachers. Among them, the online multimedia English teaching quality of $\mathrm{K} 4$ teachers improved most significantly, while the online multimedia English teaching quality of K5 and K6 teachers showed no sign of improvement from 2010 to 2011;

(4) In the future network multimedia English teaching, $\mathrm{K} 1, \mathrm{~K} 2$ and $\mathrm{K} 3$ teachers should properly improve the quality of their network multimedia English courseware; K4, K5 and K6 teachers should pay attention to improving the teaching effect of Multimedia English classroom, which is the key factor affecting the quality of network multimedia English Teaching of these six teachers.

\section{Conclusion}

This paper studies an evaluation method of English network multimedia teaching quality based on information entropy. Using the concept of conditional information entropy, a new attribute reduction method is introduced to reduce the evaluation indexes in Teachers' Network Multimedia English teaching evaluation, and some redundant evaluation indexes are removed. Reducing the subjective influence of the weight distribution of evaluation indicators considered by evaluators not only enhances the objectivity of teachers' online multimedia English teaching quality evaluation, but also does not lose its rationality, simplifies the evaluation process of teachers' online multimedia English teaching quality, reduces the evaluation workload, and then simplifies the teaching management of colleges and universities. This method can evaluate the English network multimedia teaching quality of different teachers in Colleges and universities, and analyze the impact of each evaluation index on the English network multimedia teaching quality of teachers according to the evaluation results, as well as the change of English teaching quality of teachers' network multimedia teaching level in a certain period of time. Through practical application, it is concluded that the key knowledge points are explained thoroughly, the ability to analyze and solve practical problems and the ability of innovative thinking are important indicators that have a great impact on the quality of English network multimedia teaching; K1, K2 and K3 teachers should properly improve the quality of their network multimedia English courseware; K4, K5 and K6 teachers should pay attention to improving the teaching effect of Multimedia English classroom. It provides a scientific basis for colleges and universities to select network multimedia English teachers and improve English teaching level.

\section{Acknowledgements.}

This paper is funded by Research Project of Shandong Province Social Science Program with No.20CWZJ31, Research Project of Industry-university Cooperation Education of Ministry of Education with No.202002056033.

\section{References}

[1] Hornecker, E.\&Honauer, M (2018). Creating Performance-Oriented Multimedia Projects as Part of an Interdisciplinary Teaching Practice. IEEE Multimedia, 25(2):93-103.

[2] Chen, L.Xue, J.Zhang, R. Liu, W. (2020). Reidentification risk assessment of de-identified datasets based on information entropy: Information Techology and Network Security, 39(12)1-6.

[3] Sandilos, L.E., Sims, W.A., Norwalk, K.E. \& Reddy, L.A. (2019). Converging on quality: Examining multiple measures of teaching effectiveness. Journal of School Psychology, 74:10-28.

[4] LUO, C. CHEN, Y. WANG, L. WANG, Z. CHANG, Z. (2019). Effectiveness evaluation method of systemof-systems based on operation loop and improved information entropy. Systems Engineering and Electronics, 41(01):73-80.

[5] Ingvarson, L. (2019). Teaching standards and the promotion of quality teaching. European Journal of Education, 54(293).

[6] CAI, Q. (2019). Evaluation on Teaching Quality of College English based on Triangular Fuzzy Numbers.Journal of Guizhou Normal College, 35(01):67-71.

[7] Fei, X., Yong, T.R. \& Ke, H. Y. (2018). Study of Evaluative Method of Graduate Training Quality Based on Interval-valued Fuzzy Rough Set Theory. Mathematics in Practice and Theory, 048(011):1-8.

[8] Baier, F. \& Kunter, M. (2020). Construction and validation of a test to assess (pre-service) teachers' technological pedagogical knowledge (TPK). Studies In Educational Evaluation, 67(1):100936.

[9] Ren, P., Xi, L. \& Liu, J. (2018). Research on Construction of Indicator System for Evaluation of the Ecological Civilization Education in Chinese 
Universities. Cognitive Systems Research, 52(DEC.):747-755.

[10] Gu, Y. (2019). Quantization Method of Telemetry Data Quality Dimension Based on Information Entropy. Transfusion, 38(12)42-45.

[11] Ru, T. \& Guang, W. (2019). Simulation of Support Effectiveness Evaluation of Attack Information in Mobile Self-Organizing Network. Computer Simulation, 36(02):273-276+456.

[12] Wang, C., Huang, Y., Ding, W. \& Cao, Z.J. (2021). Attribute reduction with fuzzy rough self-information measures. Information Sciences, 549(12):68-86.

[13] Liu S, He T, Dai J. A Survey of CRF Algorithm Based Knowledge Extraction of Elementary Mathematics in Chinese. Mobile Networks \& Applications, 2021, 26(5): 1891-1903

[14] Yin, L., Qin, L., Jiang, Z. \& Xu, X. (2020). A fast parallel attribute reduction algorithm using Apache Spark. Knowledge-Based Systems, 212:106582.

[15] Shuai L, Dongye L, Gautam S, et al. Overview and methods of correlation filter algorithms in object tracking. Complex \& Intelligent Systems, 2021, 7: 1895-1917

[16] Liu S, Wang S, Liu X, et al (2022). Human Inertial Thinking Strategy: A Novel Fuzzy Reasoning Mechanism for IoT-Assisted Visual Monitoring, IEEE Internet of Things Journal, online first, 10.1109/JIOT.2022.3142115

[17] Yang, M. S. \& Nataliani, Y. (2018). A FeatureReduction Fuzzy Clustering Algorithm Based on Feature-Weighted Entropy. IEEE Transactions on Fuzzy Systems, PP (99):1-1.

[18] Peng G, Jingyi L, Shuai L (2021). An Introduction to Key Technology in Artificial Intelligence and big Data Driven e-Learning and e-Education. Mobile Networks \& Applications, 26(5): 2123-2126

[19] Lang, F. K., Randles, C.A. \& Jeffery, K. A. (2020). Developing and Evaluating a Graduate Student Teaching Assistant Training Course in the Chemistry Department of a Large American University. Journal of Chemical Education, 97(6).

[20] Wang, Y. \& Shang, P. (2018). Analysis of ShannonFisher information plane in time series based on information entropy. Chaos, 28(10):103107. 